\title{
Características ambientais associadas à ocorrência de granizo em Sobradinho-RS em Dezembro de 2008
}

\author{
Environmental characteristics related to hail occurrence in Sobradinho-RS in \\ December 2008
}

\begin{abstract}
Diogo Monteiro Maria*1, Cláudia Rejane Jacondino de Campos² e Luciana Barros Pinto ${ }^{3}$
${ }^{1}$ Mestre em meteororologia pelo PPGMet - Universidade Federal de Pelotas, Brasil.

${ }^{2}$ Doutora em Física da Atmosfera/UPS- Universidade Federal de Pelotas, Brasil.

${ }^{3}$ Doutora em met Agrícola/UFV - Universidade Federal de Pelotas, Brasil.
\end{abstract}

\begin{abstract}
Resumo
Neste trabalho analisaram-se as características do ambiente termodinâmico e sinótico associado à ocorrência de granizo gerado por um Sistema Convectivo de Mesoescala (SCM) que afetou Sobradinho no Rio Grande do Sul (RS) entre os dias 09 e 10/12/08, bem como o comportamento morfológico e radiativo deste SCM. Essas análises permitiram destacar as principais condições atmosféricas que atuaram para a ocorrência deste caso. Os resultados mostraram que as condições atmosféricas observadas na região (transporte de calor e umidade em baixos níveis e correntes ascendentes intensas) foram extremamente propícias à formação e desenvolvimento do SCM, que teve início a partir do dia 09/12/08, o qual favoreceu a ocorrência de granizo no mesmo dia em Sobradinho e precipitação moderada no RS em 10/12/08.
\end{abstract}

Palavras-chave: Granizo. Sistema convectivo de mesoescala. ForTrACC

\begin{abstract}
This work analyzed thermodynamic and synoptic environmental characteristics associated with the occurrence of hail generated by a Mesoscale Convective System (MCS) that reached Sobradinho in Rio Grande do Sul (RS) from December 09 to 10, 2008 as well as morphological and radiative behavior of this MCS. These analyses allowed highlight the main atmospheric conditions which contributed for the occurrence of this event. The results showed that the atmospheric conditions observed in the region (heat and moisture transport at low levels and intense updrafts) were extremely favorable to formation and development of the MCS that began in December 09, 2008, which favored the hail occurrence on the same day in Sobradinho and precipitation in RS in December 09 to 10, 2008.
\end{abstract}

Keywords: Hail. Mesoescale convective systems. ForTrACC. 


\section{Introdução}

A

ocorrência de Eventos com Condição de enxurrada, inundação, enchente, alagamento e deslizamento, podem causar prejuízos econômicos e sociais e até mesmo perda de vidas nas regiões onde são observados (CRDCRS, 2013). Estes ES podem ocorrer associados a diversos sistemas meteorológicos, dentre eles podemse citar os Sistemas Convectivos de Mesoescala (SCM).

Os SCM são constituídos por aglomerados de nuvens convectivas que apresentam precipitação contínua em sua área de atuação, que pode ser parcialmente estratiforme e parcialmente convectiva, e possuem formas variadas (HOUZE, 1994; MACHADO; ROSSOW, 1993). Esses sistemas podem ser classificados em três categorias: Linhas de Instabilidade (LI), os que possuem forma de linha; Complexos Convectivos de Mesoescala (CCM), os que apresentam um formato circular ou simplesmente, SCM, os de formas irregulares (MADDOX, 1980; COTTON; ANTHES, 1989). Segundo Houze (1994) e Machado \& Rossow (1993) o ciclo de vida dos SCM pode ser dividido em etapas: iniciação (inclui a formação e o desenvolvimento do SCM), maturação e dissipação. Durante a formação, o sistema apresenta-se como um grupo de células isoladas, distribuídas ora de forma aleatória ora alinhadas. Em seguida, durante o desenvolvimento, as células isoladas crescem e se fundem criando regiões de intensa precipitação interligadas por regiões de menor precipitação. Quando o desenvolvimento do SCM atinge o seu máximo (etapa de maturação), observa-se precipitação estratiforme na sua retaguarda sobre uma grande região, que se mantém enquanto novas células se formam na sua parte dianteira. Quando o SCM deixa de formar novas células entram em fase de dissipação, isto é, como a formação de novas células diminui o SCM não tem como se sustentar, o que provoca seu enfraquecimento e por fim, sua dissipação.

No sul da América do Sul (AS), onde se localiza o Estado do Rio Grande do Sul (RS), os SCM são frequentes, sendo responsáveis por grande parte da precipitação nesta região (VELASCO; FRITSCH, 1987; NEBIT et al., 2006; ZIPSER et al., 2006). Estes sistemas meteorológicos podem ocorrer durante todo ano, apresentando maior frequência no período quente (Outubro a Março), devido à existência nesse período de condições favoráveis ao desenvolvimento de nuvens convectivas. Na sua maioria, apresentam duração entre 6 e $12 \mathrm{~h}$ e sua trajetória média é de oeste para leste, ou seja, do continente para o oceano (NICOLINI et al., 2002; CAMPOS; EICHHOLZ, 2011). A contribuição destes sistemas para a geração de ES é significativa, apesar disso, eles ainda não são bem previstos (CORFIDI et al., 1996; JACOBSEN; BRAUN, 2006). Um ES típico que frequentemente acompanha os SCM e que costuma causar grandes impactos econômicos e sociais nas regiões onde atua é o granizo. Tempestades de granizo podem devastar plantações inteiras em pouco tempo, tornando as colheitas irrecuperáveis (EDEN; TWIST, 1997). No RS, que possui sua economia voltada à agroindústria, é um dos Estados que mais sofre com quebra de safras causadas por ES; o granizo é um dos tipos de ES mais frequentes notificados pela Coordenadoria Regional de Defesa Civil do Estado (CRDCRS) e gerados por SCM (VARGAS Jr et al., 2011; RASERA; CAMPOS, 2013). Portanto, mostra-se de grande importância o estudo de casos de granizo associados à SCM que afetam o RS, a fim de se buscar um melhor entendimento dos mecanismos que geram esse tipo de ES, bem como um melhor conhecimento das características atmosféricas associadas à sua ocorrência.

Para a formação do granizo algumas características devem estar presentes na atmosfera como, por exemplo, transporte de calor e umidade em baixos níveis, que tornam a atmosfera instável e assim, criam um ambiente favorável ao disparo da convecção e à formação de correntes ascendentes intensas (KNIGHT; KNIGHT, 2001; WALLACE; HOBBS, 2006). Essas correntes ascendentes intensas mantêm os hidrometeoros (partículas de gelo e gotas de água) em suspensão dentro das nuvens convectivas por mais tempo, antes de precipitarem, permitindo a formação do granizo pela colisão entre essas partículas. Logo, um melhor conhecimento do ambiente atmosférico associado à formação do granizo é de grande importância na tentativa de minimizar os danos causados por ele.

Com base no exposto acima, o objetivo deste trabalho foi analisar as características do ambiente termodinâmico e sinótico associado à ocorrência de granizo em Sobradinho-RS gerada por um SCM que afetou o RS entre os dias 09 e 10/12/08, bem como o comportamento morfológico e radiativo deste SCM. A partir deste ponto este SCM é referenciado como SCM $\mathrm{GRA}_{\text {-2008. }}$.

\section{Materiais e métodos}

Para selecionar o caso de estudo utilizaram-se dados de 2004 a 2008: dos SCM que afetaram o RS $\left(\mathrm{SCM}_{\mathrm{RS}}\right)$, definidos como sendo aqueles SCM que atingiram a grade que cobre o RS, compreendida entre as latitudes de $27^{\circ}$ a $34^{\circ} \mathrm{S}$ e as longitudes de $58^{\circ}$ a $49^{\circ} \mathrm{W}$, obtidos por Campos \& Eichholz (2011); e dos SCM que afetaram o RS e que geraram granizo ( $\left.\mathrm{SCM}_{\mathrm{GRA}}\right)$, os quais foram obtidos por Rasera (2013).

A seguir descreve-se como Campos e Eichholz (2011) e Rasera (2013) selecionaram para o período de 2004 a 2008 os $\mathrm{SCM}_{\mathrm{RS}}$ e os $\mathrm{SCM}_{\mathrm{GRA}}$, respectivamente. E na sequência, como foi selecionado o caso de estudo e as análises realizadas.

\subsection{Seleção dos $\mathrm{SCM}_{\mathrm{RS}}$ entre 2004 e 2008}

Para selecionar os $\mathrm{SCM}_{\mathrm{RS}}$ entre 2004 e 2008, Campos 
e Eichholz (2011) utilizaram o aplicativo ForTraCC (Forecasting and Tracking of Active Cloud Clusters, Vila et al., 2008) no modo diagnóstico e como base de dados imagens brutas dos satélites GOES (Geostationary Operational Environmental Satellite) 10 e 12, no canal 4 (infravermelho termal), com resolução espacial de $4 \mathrm{~km}$ x $4 \mathrm{~km}$ no ponto subsatelite e resolução temporal de $1 / 2$ hora, fornecidas pela DSA/CPTEC/INPE (Divisão de Satélites e Sistemas Ambientais, do Centro de Previsão de Tempo e Estudos Climáticos, do Instituto Nacional de Pesquisas Espaciais).

O ForTrACC é um método de identificação e acompanhamento de SCM, que fornece informações sobre as características físicas e morfológicas dos SCM identificados, durante o seu ciclo de vida. É importante ressaltar que uma das principais etapas do ForTrACC é a de formação das "famílias". Nessa etapa, o programa acompanha os sistemas desde o seu surgimento até a sua dissipação, levando em consideração todas as fusões e divisões sofridas por ele ao longo do seu ciclo de vida e, a esse conjunto de sistemas (ou membros) dá-se o nome de família. Neste trabalho uma família é designada por sistema ou SCM. Portanto, cada SCM (ou família) detectado pelo ForTrACC tem seu ciclo de vida descrito pelo conjunto de características apresentadas por ele em cada instante, o qual corresponde a um membro do SCM (ou da família). O processo de identificação dos SCM pelo ForTrACC utiliza imagens brutas do satélite GOES e é baseado em limiares de tamanho (150 pixels) e temperatura de brilho do topo das nuvens- $\mathrm{T}_{\mathrm{b}}(235 \mathrm{~K}$ para identificar os SCM e 210K para identificar as células convectivas mais profundas imersas nos SCM). Segundo alguns estudos (LAURENT et al., 2002; MACHADO; LAURENT, 2004; VILA, 2004) os limiares de $T_{b}$ utilizados por Campos e Eichholz (2011) são aceitáveis para detectar nuvens associadas à convecção em diferentes regiões da América do Sul (AS), permitindo assim, a detecção tanto do SCM quanto das células convectivas imersas nele.

De todos os SCM (ou famílias) identificados pelo ForTrACC, no período de 2004 a 2008, Campos e Eichholz (2011) consideraram em seu estudo somente aqueles SCM que: i) mantiveram-se durante todo seu ciclo de vida abaixo de $20^{\circ} \mathrm{S}$; ii) apresentaram ciclo de vida de no mínimo $6 \mathrm{~h}$. Esse critério foi adotado porque além de SCM mais longos tenderem a cobrir áreas maiores (MACHADO et al., 1994; NICOLINI et al., 2002; VILA, 2004) eles podem causar eventos com precipitação intensa, fortes rajadas de vento e granizo (Silva Dias, 1999), podendo causar grandes impactos nas regiões onde atuam; iii) apresentaram iniciação espontânea e dissipação normal, isto é, tanto no momento de iniciação quanto no de dissipação, não houve interação (fusão) com outros SCM nem a separação do SCM identificado. Porém, foi permitida a existência de fusões e separações durante o ciclo de vida de um determinado SCM, uma vez que de outra maneira, o conjunto de dados a analisar seria limitado. Esse critério foi o mesmo seguido por Vila (2004) para obter um conjunto de informações mais homogêneo para estudar as características físicas dos SCM. Além disso, utilizando essa condição garante-se que o crescimento inicial dos SCM selecionados esteja associado à sua própria dinâmica interna (MACHADO; LAURENT, 2004) e, iv) afetaram o RS. Foi determinado que um SCM afetou o RS quando pelo menos um dos membros do SCM analisado apresentava latitude e longitude que o localizava dentro da grade que cobre o RS, compreendida entre as latitudes de $27^{\circ}$ a $34^{\circ} \mathrm{S}$ e as longitudes de $58^{\circ}$ a $49^{\circ} \mathrm{W}$.

Desta forma, durante o período de 01/01/2004 a 31/12/2008 Campos e Eichholz (2011) selecionaram 626 SCM com as características citadas acima $\left(\mathrm{SCM}_{\mathrm{RS}}\right)$, os quais estavam distribuídos da seguinte forma: $179 \mathrm{em}$ JFM (Jan, Fev, Mar), 150 em AMJ (abr, Mai, Jun) 142 em JAS (Jul, Ago, Set) e 155 em OND (Out, Nov, Dez).

\subsection{Seleção dos $\mathrm{SCM}_{\mathrm{GRA}}$ entre 2004 e 2008}

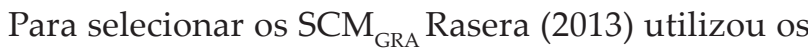
seguintes dados do período de 2004 a 2008: i) tamanho máximo, tempo de vida e trajetórias dos $\mathrm{SCM}_{\mathrm{RS}}$ selecionados por Campos e Eichholz (2011) com o uso do ForTrACC; ii) registros de granizo e municípios atingidos, notificados no banco de dados da CRDCRS e iii) imagens brutas no canal infravermelho termal dos satélites GOES 10 e 12, com resolução espacial de 4 km x $4 \mathrm{~km}$ no ponto subsatelite e resolução temporal de $1 / 2$ hora, fornecidas pela DSA/CPTEC/INPE.

Para verificar quais dos $626 \mathrm{SCM}_{\mathrm{RS}}$ no período de 2004 a 2008 geraram granizo $\left(\mathrm{SCM}_{\mathrm{GRA}}\right)$, Rasera (2013) adotou o seguinte procedimento. Primeiramente organizou as informações sobre o tamanho máximo, tempo de vida e trajetória de cada $\mathrm{SCM}_{\mathrm{RS}}$ em uma planilha eletrônica. Em seguida verificou se no(s) dia(s) que foi observado cada um dos $\mathrm{SCM}_{\mathrm{RS}}$, houve registro de granizo notificado no banco de dados da CRDCRS. Tendo sido verificada a ocorrência de granizo dentro do período compreendido pelo ciclo de vida do $\mathrm{SCM}_{\mathrm{RS}}$ então identificou os municípios atingidos, e plotou suas latitudes e longitudes em um mapa. Em seguida neste mesmo mapa plotou a trajetória do $\mathrm{SCM}_{\mathrm{RS}}$ em análise (utilizando para isso as latitudes e longitudes de todos os seus membros), para acompanhar a evolução do seu ciclo de vida e verificar se este sistema estava atuando sobre os municípios atingidos. Visando maior precisão na verificação dos municípios atingidos pelo $\mathrm{SCM}_{\mathrm{RS}}$ em análise, no mesmo mapa foram sobrepostas as imagens dos satélites GOES com temperatura de brilho realçada abaixo de 235K (limiar utilizado para detectar SCM) de todo o ciclo de vida do $S C M_{R S}$. Quando constatou que o $S C M_{R S}$ em análise afetou o(s) município(s) que registrou(ram) granizo, então classificou este $\mathrm{SCM}_{\mathrm{RS}}$ como um SCM que afetou o RS e que gerou granizo $\left(\mathrm{SCM}_{\mathrm{GRA}}\right)$. Esse mesmo procedimento foi utilizado para selecionar os SCM que 
geraram além de granizo, os seguintes eventos severos: granizo/vendaval (ocorrência simultânea dos dois eventos), vendaval, enxurrada, inundação, enchente, alagamento e deslizamento.

Utilizando a metodologia citada acima, Rasera (2013) observou que dos 626 SCM $_{\mathrm{RS}}, 29$ geraram granizo (SCMGRA) e 38 geraram os outros tipos de ES citados acima $\left(\mathrm{SCM}_{\mathrm{ES}}\right)$. Além disso, este autor observou que os SCM $\mathrm{GRA}_{\mathrm{G}}$ estavam distribuídos da seguinte forma: 6 em AMJ, 13 em JAS e 10 em OND.

\subsection{Seleção do caso de estudo e análises reali- zadas}

Os critérios utilizados para a seleção do caso de estudo, basearam-se primeiro na sua ocorrência ter se dado em um dos períodos do ano com maiores frequências de $S C M_{\text {GRA }}$ e depois na maior duração e maior tamanho do mesmo. Além disso, procurou-se selecionar um caso cujas etapas de iniciação, maturação e dissipação ocorressem em horários o mais próximo possível dos horários sinóticos em que são disponibilizados os dados de reanálise global geradas no NCEP-CFSR (National Centers for Environmental Prediction - Climate Forecast System Reanalysis, http://nomads.ncdc.noaa.gov/ data.php? name=access\#cfsr). Assim foi selecionado um

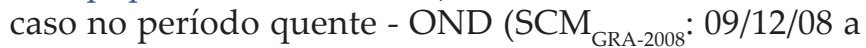
10/12/08), que se encaixou nos critérios definidos acima.

Após a seleção do SCM ${ }_{\mathrm{GRA}-2008^{\prime}}$ foram utilizados dados diários de precipitação pluvial acumulada em 24 horas (o total de precipitação de um determinado dia, corresponde ao valor acumulado entre as 12 UTC do dia anterior e as 12 UTC daquele dia), de 16 Estações Meteorológicas de Superfície (EMS) pertencentes ao $8^{\circ}$ DISME/INMET ( $8^{\circ}$ Distrito de Meteorologia/Instituto Nacional de Meteorologia), do período de 09/12/08 a 11/12/08. Essas 16 EMS foram escolhidas por pertencerem a diferentes regiões ecoclimáticas (regiões com características climáticas semelhantes) do RS (Figura 1). Esses dados serviram para se verificar os valores de precipitação que foram registrados no RS, antes, durante e após a atuação do SCM GRA-2008. $_{\text {. }}$

Para analisar o ambiente termodinâmico associado à ocorrência do caso de estudo se analisou alguns índices de instabilidade que funcionam como ferramentas diagnósticas da possibilidade de formação de tempestades severas que podem gerar granizo. Os índices de instabilidade analisados foram CAPE (Convective Available Potential Energy; NASCIMENTO, 2005) que fornece uma medida direta da energia potencial disponível para o desenvolvimento da atividade convectiva; índice de levantamento (Lifted Index, LI; GALWAY, 1956) e Showalter (IS, HENRY, 1987) que denotam a instabilidade da camada e são negativos quando há umidade e calor nos níveis baixos da atmosfera e ar frio em 850 hPa; índice $\mathrm{K}$ que é significativo quando há calor em baixos níveis da atmosfera e umidade em abundância desde a superfície até 700 hPa e Total Totals (TT, HENRY, 1987) que exige calor e umidade em $850 \mathrm{hPa}$ e frio em $500 \mathrm{hPa}$ e não restringe a umidade em $700 \mathrm{hPa}$ e, denota o potencial

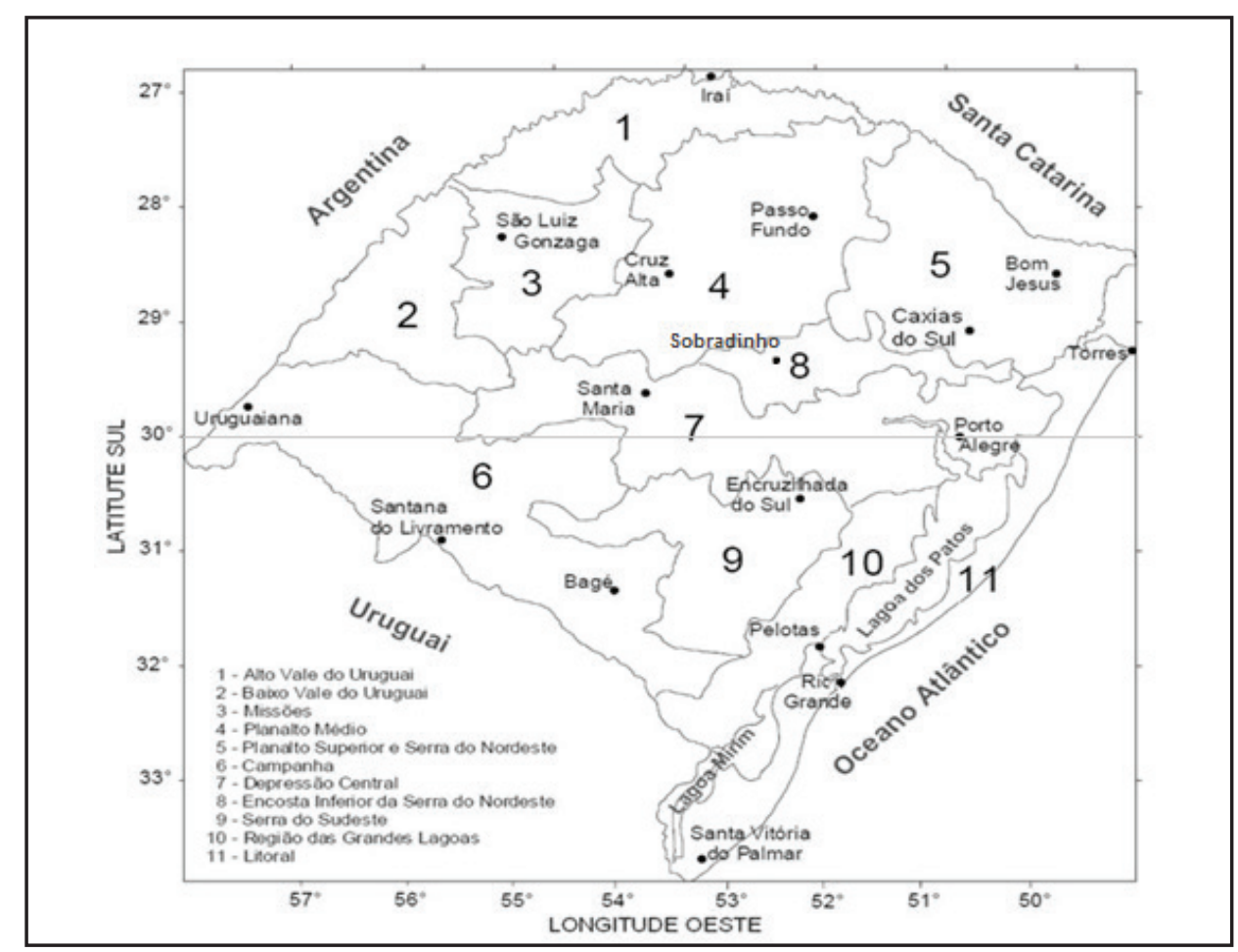

Figura 1. Distribuição espacial das estações meteorológicas utilizadas neste trabalho, em suas respectivas Regiões Ecoclimáticas.

Fonte: Rio Grande do Sul (1994) 
da atmosfera para formação de tempestades severas. Analisou-se ainda o nível de congelamento, ou seja, a altura onde a temperatura do bulbo úmido $\left(\mathrm{T}_{\mathrm{W}}\right)$ atinge $0^{\circ} \mathrm{C}$, uma vez que a ocorrência de granizo está associada a esta altura (FAWBUSH; MILLER, 1953). Escolheu-se o horário das 12 UTC do dia 09/12/08 para a análise dos índices e do nível de congelamento, tendo em vista que a queda de granizo ocorreu no dia 09/12/08 (informações da CRDCRS). Os dados aerológicos utilizados nestas análises foram relativos à radiossondagem realizada na estação de Santa Maria $\left(29,68^{\circ} \mathrm{S}\right.$ e $\left.53,80^{\circ} \mathrm{W}\right)$ às 12 UTC do dia 09/12/08 (radiossondagem disponível, mais próxima a Sobradinho), obtidos em http://weather.uwyo.edu/ upperair/sounding.html. Ressalta-se que Sobradinho esta localizada a $110 \mathrm{~km}$ de Santa Maria. Como o SCM em análise atuou sobre os dois municípios, a radiossondagem realizada em Santa Maria serviu para representar as características do ambiente também em Sobradinho.

Na sequência utilizou-se o aplicativo ForTrACC no modo diagnóstico e imagens do satélite GOES 10 no canal infravemelho termal, com resolução espacial de $4 \mathrm{~km} \times 4$ km no ponto subsatelite e resolução temporal de $15 \mathrm{~min}$, do período de atuação do $\operatorname{SCM}_{\text {GRA-2008 }}(09$ a 10/12/08) para gerar informações que permitiram analisar o ciclo de vida, trajetória (acompanhamento da posição do SCM $\mathrm{GRA-2008}$ em cada instante do seu ciclo de vida, desde a iniciação até a dissipação) e deslocamento (considerou-se apenas as posições do $\mathrm{SCM}_{\mathrm{GRA-2008}}$ nos instantes de iniciação, maturação e dissipação) do SCM ${ }_{\text {GRA-2008 }}$ em estudo, bem como a evolução temporal do seu tamanho (dado pelo número de pixels com temperatura de brilho inferior a $235 \mathrm{~K})$, da temperatura de brilho mínima do topo das nuvens $\left(\mathrm{T}_{\text {bmim }}\right)$ e da fração convectiva. A relação entre a área ocupada pelos topos frios (pixels com $\mathrm{T}_{\mathrm{b}}$ inferior a $210 \mathrm{~K}$ ) e a área total do SCM (pixels com $\mathrm{T}_{\mathrm{b}}$ inferior a $235 \mathrm{~K}$ ) é definida como fração convectiva, a qual representa o tamanho relativo dos núcleos ativos do SCM e evidencia o horário em que o SCM atingiu seu período com convecção mais intensa.

Utilizaram-se também campos de refletividade (dBZ) do radar meteorológico de Canguçu, pertencente à REDEMET (Rede de Meteorologia do Comando da Aeronáutica, http://www.redemet.aer.mil.br/radar/radar. php?chave=MjAxMzExMDYxNjE4MDM=\&ID_REDEMET=e04711jdf25ohu46lq40u5gph2\&data=09/12/2008\#) do dia 09/12/08 para analisar a atividade convectiva associada a ocorrência de granizo.

Por fim, para a análise do ambiente em grande escala

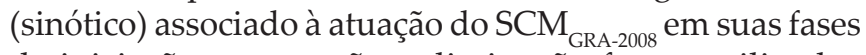
de iniciação, maturação e dissipação foram utilizados dados de reanálise global geradas no NCEP-CFSR (http:// nomads.ncdc.noaa.gov/data.php?name=access\#cfsr), com resolução espacial de $0,5^{\circ} \times 0,5^{\circ}$ e disponibilizados de 6 em 6 horas $(00,06,12$ e 18 UTC). Com esses dados foram gerados campos meteorológicos dos horários mais próximos das etapas de iniciação, maturação e dissipação do SCM ${ }_{\text {GRA-2008. }}$ Os campos utilizados foram: pressão em superfície e vento em 10 metros, para analisar a posição dos centros de alta e baixa pressão na região de atuação do SCM GRA-2008; $_{\text {; }}$ advecção de temperatura e convergência de umidade e vento em $850 \mathrm{hPa}$, que indicam locais propensos à ocorrência de convecção, uma vez que a adveção quente e a convergência de umidade (transporte de calor e umidade em baixos níveis) tornam a atmosfera instável e criam um ambiente favorável à formação e desenvolvimento de SCM (JIRAK; COTTON, 2004); velocidade vertical (Omega) em $500 \mathrm{hPa}$, para analisar os movimentos verticais do ar que expressam o nível de estabilidade/instabilidade atmosférica presente. Logo, regiões com movimento do ar ascendente (velocidade vertical negativa) estão associadas à instabilidade atmosférica e ao favorecimento do disparo da convecção em baixos níveis (UCELLINI; JOHNSON, 1979); e divergência do vento em $200 \mathrm{hPa}$, que indica se na superfície há convergência de umidade e calor que geram movimentos verticais ascendentes, evidenciando a atividade convectiva de uma região (LIMA et al., 2003).

\section{Resultados e discussão}

A análise dos dados diários de precipitação pluvial acumulada observados nos dias 09, 10 e 11/12/08, das 16 EMS utilizadas neste estudo (Figura 1), mostrou que no dia 10/12/08 foram observados os maiores valores de precipitação Ao analisar a composição da precipitação pluvial acumulada (mm) observada no dia 10/12/08 (Figura 2) percebe-se que esta estava distribuída em todo o Estado com núcleos mais intensos nas regiões norte e centro-sul do RS. Pôde-se notar ainda, que as EMS de

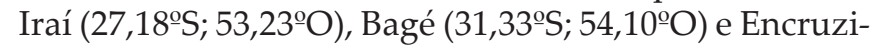
lhada do Sul $\left(30,54^{\circ} \mathrm{S} ; 52,52^{\circ} \mathrm{O}\right)$ foram as que observaram os maiores valores de precipitação acumulada no dia 10/12/08 (acumulado entre 12 UTC do dia 09/12/08 e 12 UTC do dia 10/12/08): 33,2 mm; 28,4 mm e 25,0 mm, respectivamente. Esses valores correspondem a $24,1 \%$, $28,7 \%$ e $26,9 \%$, respectivamente, do total de precipitação esperado para o mês de dezembro nestas EMS (Ramos et al., 2009). Destaca-se que destas 3 EMS, Encruzilhada do Sul é a mais próxima ao município de Sobradinho $\left(29,42^{\circ} \mathrm{S} ; 53,02^{\circ} \mathrm{O}\right)$, onde segundo o boletim registrado pela CRDCRS, no dia 09/12/08 houve ocorrência de granizo, que afetou a área rural do município, causando danos em lavouras de fumo, milho, feijão, pessegueiro, parreirais e hortaliças.

Na sequência analisou-se o ambiente termodinâmico associado ao caso de estudo utilizando índices de instabilidade e o nível de congelamento. Os valores de referência dos índices de instabilidade encontrados na literatura para detecção de tempestades severas que podem gerar granizo (CAPE $>100$ : BROOKS et al., 2003 e LI e IS>0, K>24, TT>50: Silva Dias, 2000) e os valores destes índices obtidos pela radiossondagem de Santa Maria para o dia 09/12/08 às 12 UTC foram confrontados 


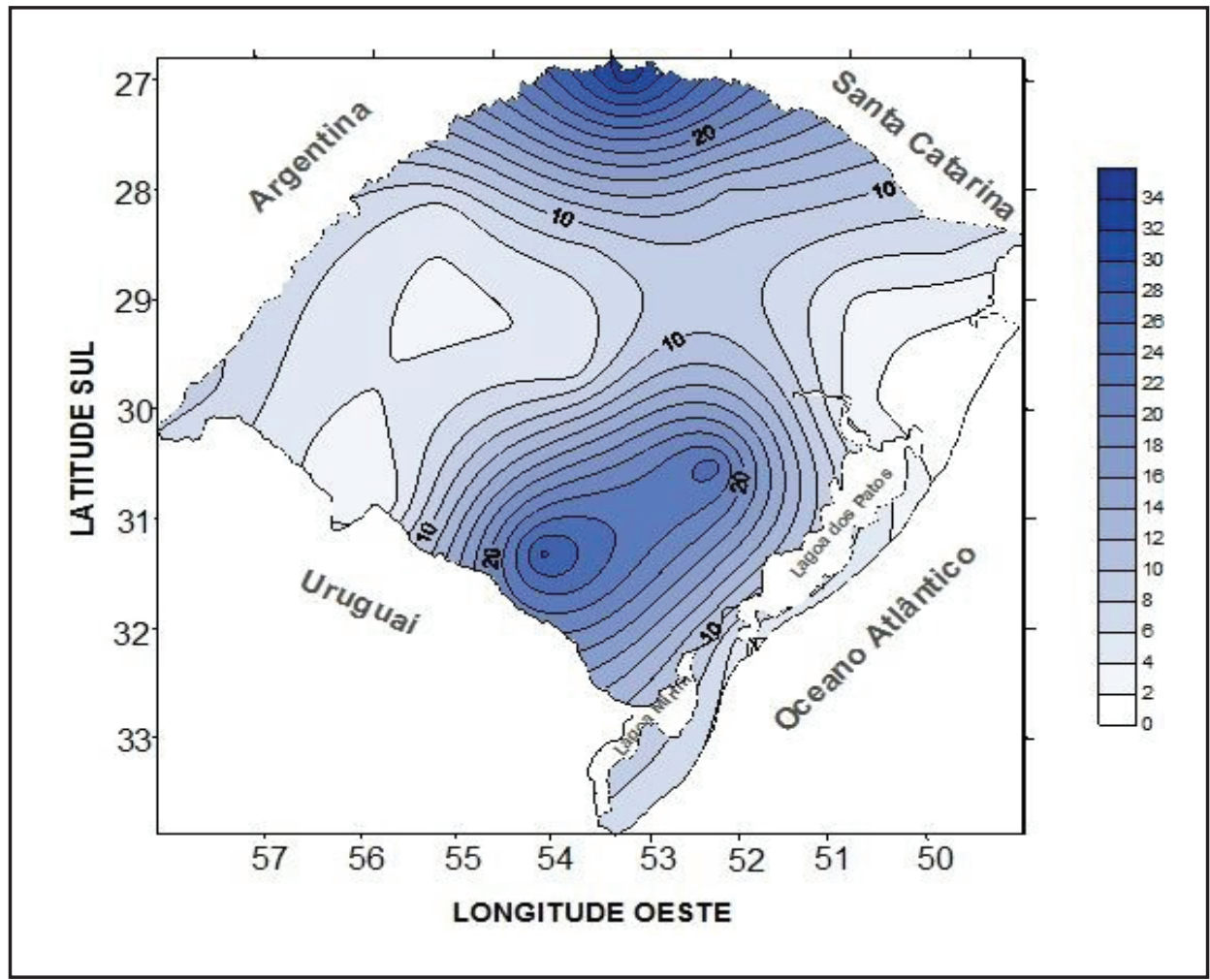

Figura 2 - Composição da precipitação pluvial acumulada (mm) registrada no dia 10/12/08, para 16 estações meteorológicas de superfície do Rio Grande do Sul

(Tabela 1). Pode-se notar que os valores dos índices de instabilidade obtidos para o dia 09/12/08 às 12 UTC, quando comparados com os seus valores de referência apresentados na literatura, indicavam que o ambiente termodinâmico continha os ingredientes necessários para o desenvolvimento de tempestade severa com potencial para gerar granizo (Tabela 1). Ou seja, existia energia potencial disponível para o desenvolvimento da atividade convectiva $\left(\mathrm{CAPE}=491 \mathrm{JKg}^{-1}\right)$. Apesar do limiar mínimo para CAPE documentado por Nascimento (2005) para detecção de tempestades severas em diversas regiões do globo ser de $1.000 \mathrm{~J} \mathrm{Kg}^{-1}$, Brooks et al. (2003), que mapearam as regiões mais propensas ao desenvolvimento de tempestades severas a partir do uso de índices para o globo, mostraram que para a AS o limiar mínimo de CAPE é $100 \mathrm{~J} \mathrm{Kg}^{-1}$. Os índices LI e IS negativos $\left(-2^{\circ} \mathrm{C}\right)$ indicavam que havia instabilidade na atmosfera com a presença de umidade e calor nos níveis baixos da atmosfera. $\mathrm{O}$ índice $\mathrm{K}=34,9^{\circ} \mathrm{C}$ indicava que havia calor em baixos níveis e umidade em abundância desde a superfície até $700 \mathrm{hPa}$. O índice $\mathrm{TT}=51,6^{\circ} \mathrm{C}$ mostrava que havia condições para formação de tempestades severas. Todos esses fatores em conjunto davam condições à ocorrência de granizo no dia 09/12/08 e precipitação moderada em 10/12/08 no RS.

Outro fator que condicionou a ocorrência de granizo no dia 09/12/08 em Sobradinho foi a altura em que a Tw atingiu $0^{\circ} \mathrm{C}$, ou seja, altura do nível de congelamento que indica a possibilidade de formação de granizo.
Tabela 1 - Índices de instabilidade: $(1)^{*}$ valores de referência na literatura para detecção de tempestades severas que podem gerar granizo e (2) obtidos pela radiossondagem da estação de Santa Maria para o dia 09/12/08 à 12 UTC

\begin{tabular}{lccccc}
\hline & $\mathrm{CAPE}\left(\mathrm{J} \mathrm{Kg}^{-1}\right)$ & LI & IS & $\mathrm{K}\left({ }^{\circ} \mathrm{C}\right)$ & $\mathrm{TT}\left({ }^{\circ} \mathrm{C}\right)$ \\
\hline$(1)^{*}$ & 100 & $<0$ & $<0$ & $>24$ & $>50$ \\
$(2)$ & 491 & -2 & -2 & 34,9 & 51,6 \\
\hline${ }^{*}$ CAPE (BROOKS et al., 2003) & e LI, SI, K, TT (SILVA DIAS, 2000)
\end{tabular}

Segundo Fawbush \& Miller (1953) para haver formação de granizo, $\mathrm{Tw}=0^{\circ} \mathrm{C}$ tem que estar a uma altura acima da superfície entre 2.000 e $3.500 \mathrm{~m}$. No presente caso esta altura estava em aproximadamente $3.500 \mathrm{~m}$ (ver seta vermelha na Figura 3), portanto indicando que na atmosfera havia condições para a formação de granizo.

Na sequência a evolução da nebulosidade associada ao $\mathrm{SCM}_{\text {GRA-2008 }}$ que atuou no RS entre os dias 09 e 10/12/08 foi analisada utilizando imagens do satélite GOES 10 (Figura 4) e imagens de refletividade do radar de Canguçu (Figura 5). Observa-se que no dia 09/12/08 às 09 UTC (Figura 4A) havia a presença de células convectivas isoladas no nordeste da Argentina que dariam origem ao $\mathrm{SCM}_{\mathrm{GRA}-2008}$. Às 12:15 UTC do dia 09/12/08 (Figura 4B) o ForTrACC detectou o início do SCM que gerou queda de granizo no mesmo dia e valores de precipitação moderados no RS no dia 10/12/08. Na iniciação a nebulosidade associada 


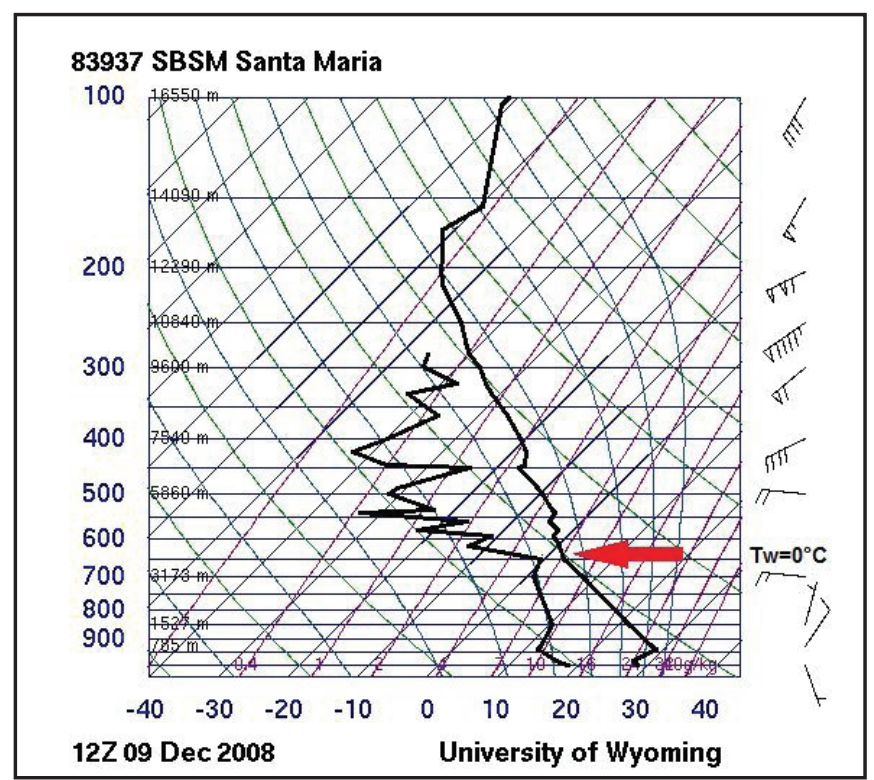

Figura 3 - Radiossondagem da estação de Santa Maria-RS no dia 09/12/2008 à 12 UTC. A seta em vermelho indica a altura da isolinha da temperatura do bulbo úmido de $0^{\circ} \mathrm{C}$. Fonte: (http://weather.uwyo.edu/upperair/sounding. html) ao $\mathrm{SCM}_{\mathrm{GRA}-2008}$ estava mais localizada no nordeste da Argentina e já começava a atingir o Uruguai. A partir das 16:15 UTC do dia 09/12/08 o SCM ${ }_{\text {GRA-2008 }}$ começava a atuar sobre o RS (Figura 4C). Entre as 19:15 e 21:45 UTC (Figura 4D,E,F) observa-se que sobre todo o RS havia a presença de nuvens com topos mais frios (abaixo de $210 \mathrm{~K})$ e portanto, com maior desenvolvimento vertical, que indicavam a presença de núcleos convectivos em algumas regiões do Estado como por exemplo, na região de Sobradinho (ponto vermelho na Figura 4D,E,F) onde houve queda de granizo que foi favorecida pela presença dessa nebulosidade. Nesses horários podem-se observar núcleos de refletividade mais elevados, localizados na região de Sobradinho (Figura 5). O momento da máxima extensão do SCM ${ }_{\text {GRA-2008 }}$ (fase de maturação) foi detectado pelo ForTrACC no dia 09/12/08 às 22:15 UTC, quando este cobria todo o RS (Figura 4G). Pode-se notar que as nuvens com topos mais frios foram detectadas sobre o RS entre as fases de iniciação e maturação do SCM ${ }_{\text {GRA-2008' }}$ no dia 09/12/08 (Figura 4D,E,F; Figura 5A,B,C), quando foi registrada a queda de granizo em Sobradinho. Ou seja, o sistema primeiro sofreu uma forte convecção para depois se expandir no estágio de maturação, comportamento semelhante ao observado por outros autores

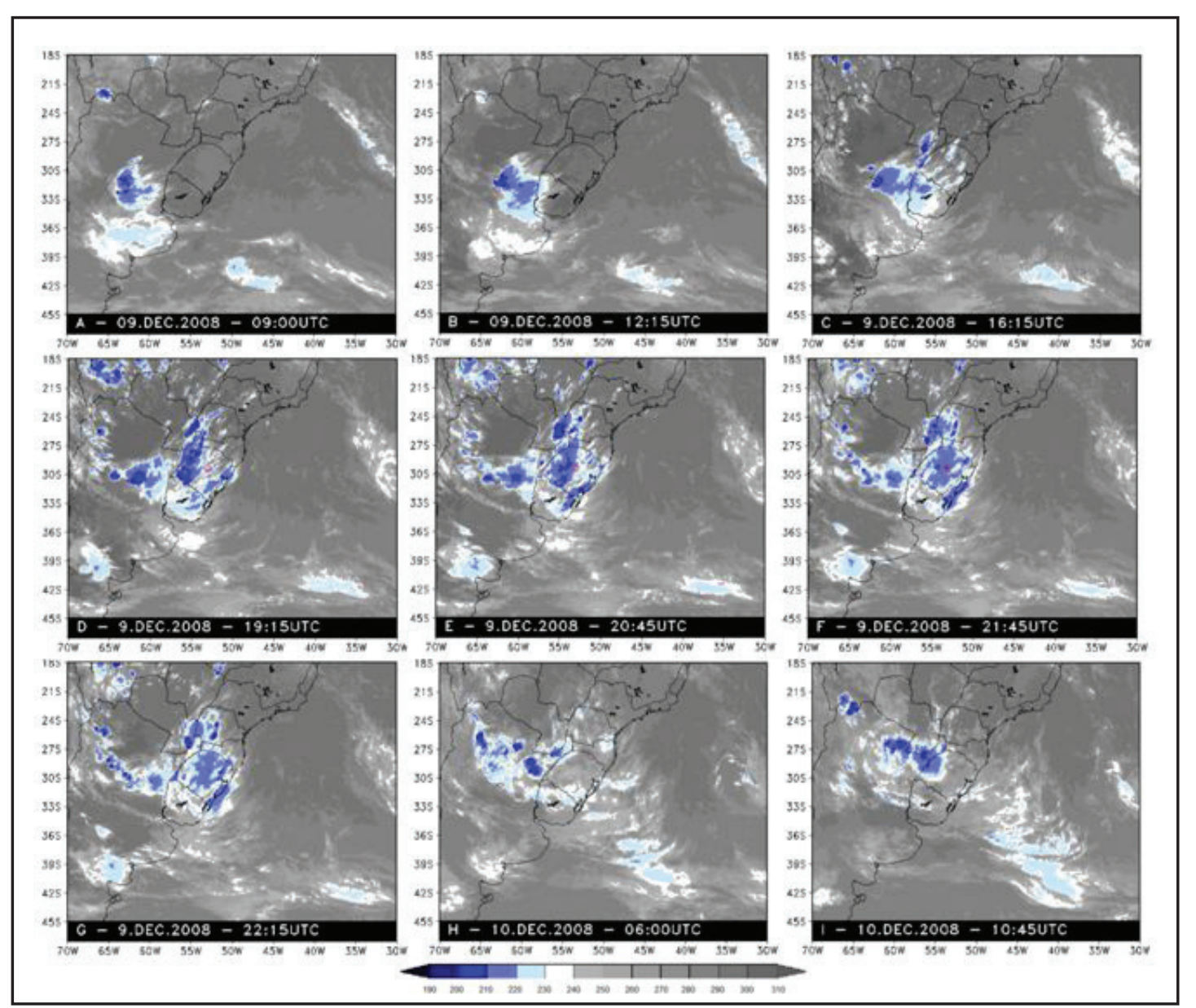

Figura 4 - Imagens do satélite GOES 10 no canal 4, mostrando a evolução do SCM ${ }_{\text {GRA-2008 }}$ entre os dias 09 e 10/12/08 sobre o RS. O círculo vermelho nas figuras D, E, F representa a localização do município de Sobradinho, onde houve queda de granizo 


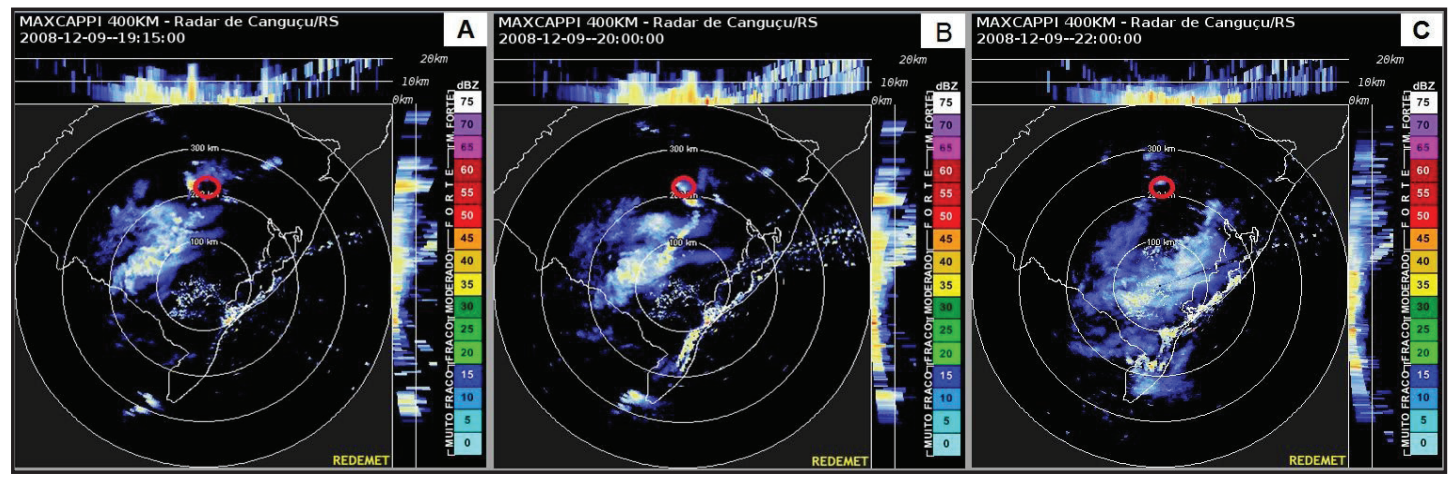

Figura 5 - Imagens de refletividade (dBZ) do radar meteorológico de Canguçu (REDEMET) entre as 19:15 UTC e as 22 UTC do dia 09/12/08. Círculo vermelho representa a localização de Sobradinho

(MACHADO; ROSSOW, 1993; PINTO; CAMPOS, 2009). Após atuar sobre o sul do Brasil, o ForTrACC detectou a dissipação do $\mathrm{SCM}_{\mathrm{GRA}-2008}$ sobre o Oceano Atlântico no dia 10/12/08 às 10:45 UTC (Figura 4I), totalizando um ciclo de vida de 22,5 horas.

Pôde-se observar analisando a trajetória (Figura 6A) e o deslocamento (Figura 6B) do $\mathrm{SCM}_{\mathrm{GRA}-2008}$ que este se formou no nordeste da Argentina no dia 09/12/08, atingiu sua máxima extensão sobre o RS, oeste de SC e PR no dia 10/12/08 e dissipou-se no Oceano Atlântico no dia 10/12/08 (Figura 6A). Portanto, o SCM GRA-2008 $_{\text {apresentou }}$ deslocamento de oeste para leste (Figura 6B), seguindo o deslocamento médio observado por diversos autores (VELASCO; FRITSCH, 1987; NICOLINI et al., 2002; SIQUEIRA; MARQUES, 2008; CAMPOS; EICHHOLZ, 2011), para essa mesma região. Siqueira \& Marques (2008) observaram que a circulação predominantemente zonal acima de $500 \mathrm{hPa}$ favorece o deslocamento zonal (de oeste para leste) observado na maioria dos SCM, devido a influência dinâmica ser mais forte do que a influência termodinâmica na região de estudo. Estes autores observaram que as trajetórias dos SCM que se desenvolvem na AS são predominantemente, do continente para o oceano, influenciados por Sistemas
Frontais (SF) e forçantes associadas a contrastes térmicos e a estratificação atmosférica em grande escala. No presente estudo observou-se que o SCM analisado não estava associado à incursão de SF e foi modulado pelo aquecimento diurno. Esse tipo de SCM segundo Siqueira e Marques (2008) são mais frequentes nos períodos quentes (JFM e OND), quando há a presença de fortes ventos de oeste-noroeste em direção ao Oceano Atlântico Tropical (entre as latitudes de $5^{\circ} \mathrm{S}$ a $40^{\circ} \mathrm{S}$ e longitudes de $30^{\circ} \mathrm{W}$ a $65^{\circ} \mathrm{W}$ ), que tendem a mover os SCM para leste, como

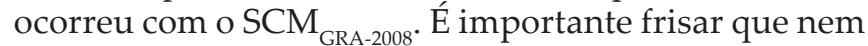
todos os SCM seguem o deslocamento médio de oeste para leste, uma vez que fatores termodinâmicos podem influenciar no seu deslocamento, como a circulação marterra (SIQUEIRA; MARQUES, 2008).

Para uma melhor descrição do $\mathrm{SCM}_{\mathrm{GRA} A-2008^{\prime}}$ têm-se as Figuras 7 e 8, que mostram a evolução temporal de alguns de seus parâmetros morfológicos e radiativos ao longo do seu ciclo de vida: tamanho e $\mathrm{T}_{\text {bmin }}$ (Figura 7) e fração convectiva (Figura 8).

Na Figura 7 nota-se que a partir da iniciação (detectada pelo ForTrACC às 12:15 UTC do dia 09/12/08) há um decréscimo da $\mathrm{T}_{\text {bmin' }^{\prime}}$ enquanto que o tamanho do $\mathrm{SCM}_{\text {GRA-2008 }}$ aumenta. No momento anterior a etapa de

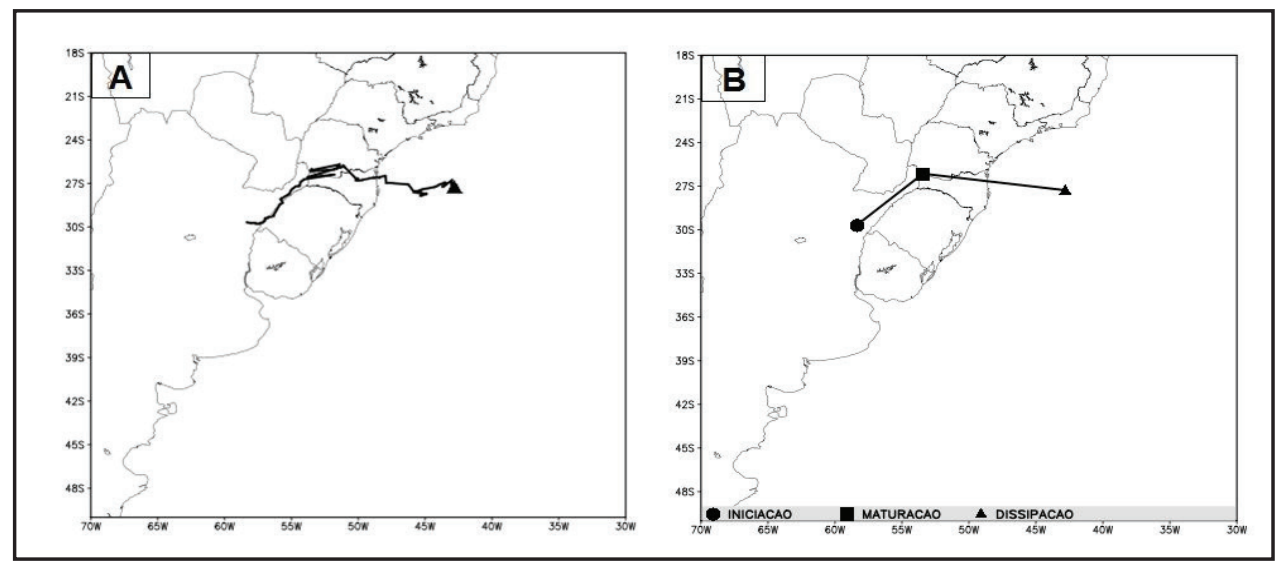

Figura 6 - Trajetória (A) e deslocamento (B) seguidos pelo $\mathrm{SCM}_{\mathrm{GRA-2008}}$ ao longo do seu ciclo de vida entre os dias 09 e $10 / 12 / 08$ 
maturação (19:30 UTC do dia 09/12/08) a $\mathrm{T}_{\text {bmin }}$ atinge seus menores valores ( $192 \mathrm{~K})$, ou seja, primeiramente o sistema alcançou seu máximo resfriamento e logo em seguida se expandiu, atingindo seu tamanho máximo na maturação (detectada pelo ForTrACC as 22:15 UTC do dia 09/12/08), conforme observado por Machado e Rossow (1993) e Pinto e Campos (2009). Após a maturação a $\mathrm{T}_{\text {bmin }}$ se eleva e o tamanho diminui até o momento da dissipação (detectada pelo ForTrACC às 10:45 UTC do dia 10/12/08). Os menores valores de $T_{\text {bmin }}$ observados entre as fases de iniciação e maturação indicavam nuvens com topos frios, que apresentavam condições favoráveis à formação de granizo em 09/12/08 e precipitação moderada em 10/12/08.

A análise da evolução da fração convectiva do SCMGRA-2008 (Figura 8) mostra na iniciação (detectada pelo ForTrACC às 12:15 UTC do dia 09/12/08) valores médios e vários picos próximos à maturação. Pôde-se observar, ainda pelos dados gerados pelo ForTrACC, que no final da fase de iniciação e durante a fase de maturação o SCM ${ }_{\text {GRA-2008 }}$ sofreu fusão com vários outros SCM que se formaram e estavam atuando na região. Essa fusão provocou o aumento da fração convectiva do SCM $\mathrm{GRA-2008}_{\text {. }}$ que foi observado nos dias 09 e 10/12/08 e, portanto, a ocorrência de granizo e precipitação moderada no RS. Na dissipação (detectada pelo ForTrACC às 10:45 UTC do dia 10/12/08) a fração convectiva apresentou valor próximo à zero indicando que a convecção havia cessado.

Cabe ressaltar que o ForTrACC pode gerar imagens virtuais que visam completar um período de ausência de até 6 imagens de satélite durante o rastreamento de um SCM. Como o intervalo entre as imagens do satélite GOES 10 utilizadas neste estudo é de 15 minutos, o período máximo de preenchimento possível era de $1,5 \mathrm{~h}$. No presente estudo observou-se que não havia imagens do satélite GOES 10 disponíveis no período das 9:00 UTC às 12:15 UTC (intervalo de 3,25 h de ausência de imagens) do dia 09/12/08. Portanto, o ForTrACC não pode rastrear o SCM desde os momentos iniciais do seu desenvolvimento, detectando-o apenas às 12:15 UTC do dia 09/12/08. Por essa razão, os valores de tamanho e fração convectiva já se encontravam elevados no instante

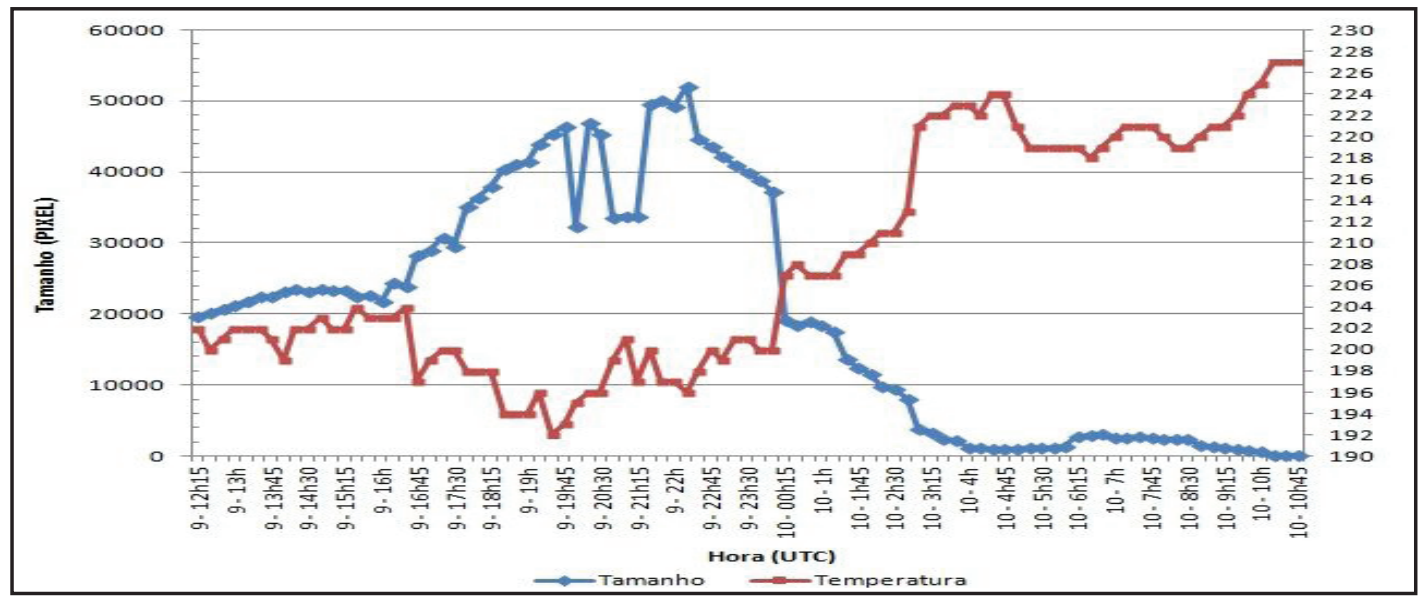

Figura 7 - Evolução temporal do tamanho (em número de pixels com temperatura abaixo de $235 \mathrm{~K}$ ) e da temperatura de brilho mínima (abaixo de $235 \mathrm{~K}$ ) do SCM que atingiu o RS entre às 12:15 UTC do dia 09/12/08 e às 10:45 UTC do dia 10/12/08

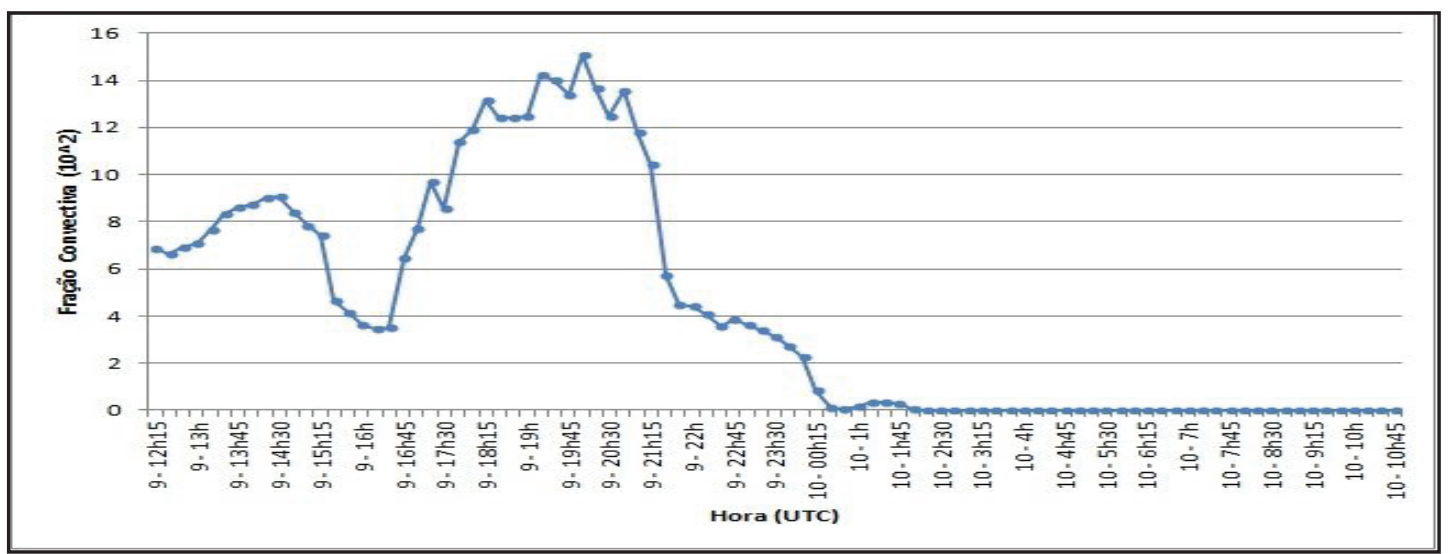

Figura 8 - Evolução temporal da fração convectiva do SCM ${ }_{\text {GRA-2008 }}$ entre 12:15 UTC do dia 09/12/08 e às 10:45 UTC do dia 10/12/08 
da iniciação do SCM ${ }_{\text {GRA-2008 }}$ detectada pelo ForTrACC.

A análise do ambiente em grande escala (sinótico) associado à atuação do SCM ${ }_{\text {GRA-2008 }}$ mostrou que na sua fase de iniciação (Figuras 9A, 10A, 11A, 12A e 13A), detectada pelo ForTrACC às 12:15 UTC do dia 09/12/08, foi observado em 850 hPa um Jato de Baixos Níveis (JBN) de norte que advectava calor e umidade para o nordeste da Argentina, região de formação do SCM ${ }_{\mathrm{GRA}-2008}$. Este JBN estava associado a um centro de baixa pressão (Figura 9A) que começou a se formar a partir do dia 07/12/08 no nordeste da Argentina (região de formação do SCMGRA) e que se intensificou nos dias 08 e 09/12/08 (Síntese Sinótica Mensal - CPTEC, http://www.cptec.inpe.br/ noticias/noticia/10160). Nessa região podem-se notar valores elevados de advecção quente de temperatura (Figura 10A) e de convergência de umidade específica (Figura 11A). Ainda na fase de iniciação, em 500 hPa, pode-se notar que a velocidade vertical se encontrava

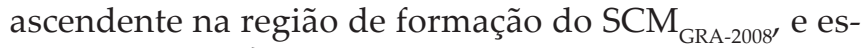
tava associada à formação do centro de baixa pressão em superfície, favorecendo o levantamento da parcela de ar (Figura 12A). No campo de divergência do vento em $200 \mathrm{hPa}$, pode-se observar que havia a presença do Jato de Altos Níveis (JAN) e divergência do vento, na região de formação do SCM, indicando a existência de convecção em níveis inferiores (Figura 13A). Portanto, o ambiente na iniciação mostrava condições favoráveis ao desenvolvimento do SCM $\mathrm{GRA-2008}_{\text {, }}$ ou seja, convergência em baixos níveis forçada pelo JBN e movimento vertical ascendente que favoreceu a instabilidade atmosférica no local de formação do sistema.

Na maturação (Figuras 9B, 10B, 11B, 12B e 13B), detectada pelo ForTrACC às 12:15 UTC do dia 09/12/08, o centro de baixa pressão no norte da Argentina se intensificou (Figura 9B) e em $850 \mathrm{hPa}$ ainda havia a atuação do JBN (localizado mais ao norte em relação ao estágio de iniciação) que advectava ar quente (Figura 10B) e úmido (Figura 11B) para o nordeste da Argentina e norte do RS. Havia também nesta fase divergência do vento no nível de $200 \mathrm{hPa}$ (Figura 13B), associada ao forte movimento vertical em $500 \mathrm{hPa}$ (Figura 12B), indicando a presença de atividade convectiva sobre a região de maturação do $\mathrm{SCM}_{\mathrm{GRA-2008}}$ devido as nuvens de topos frios observadas nessa fase na região. Portanto, as condições observadas na maturação favoreceram a fusão dos vários SCM que se formaram sobre a região

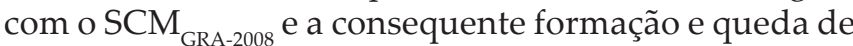
granizo em 09/12/08 e precipitação em 10/12/08 no RS.

Após a fase de maturação o $\mathrm{SCM}_{\mathrm{GRA}-2008}$ entrou em processo de dissipação (detectado pelo ForTrACC às 10:45 UTC do dia 10/12/08). Nesta fase o centro de baixa pressão perdeu intensidade (Figura 9C) e o campo de

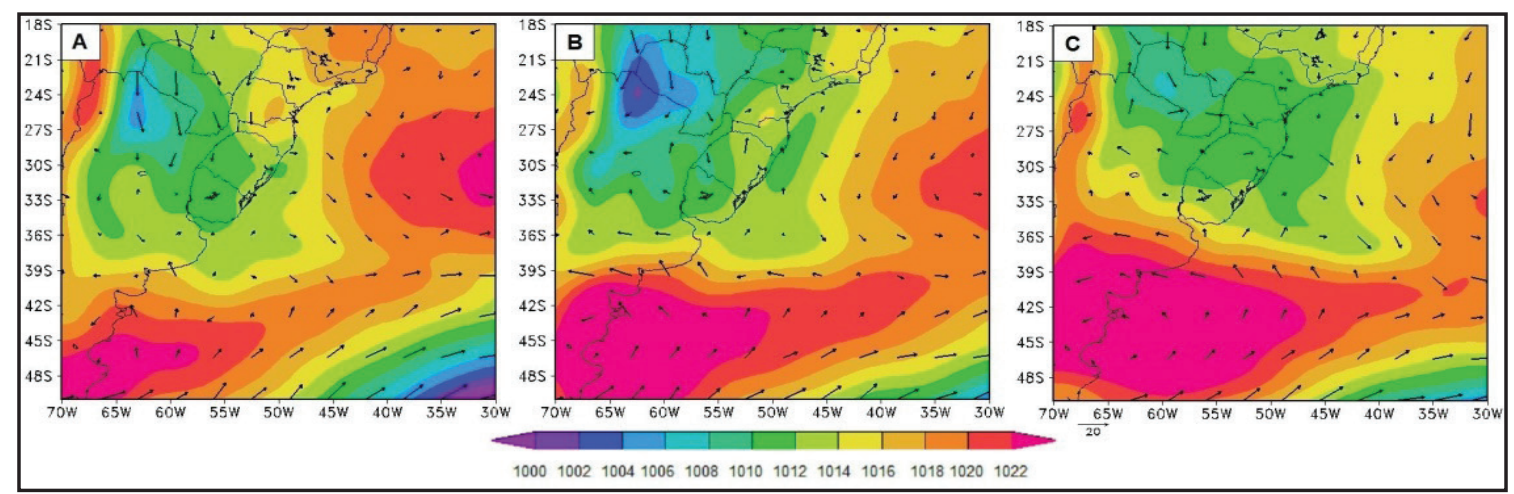

Figura 9. Pressão atmosférica (hPa) à superfície e vetor vento em $10 \mathrm{~m}\left(\mathrm{~ms}^{-1}\right)$ : (A) 09/12/08 às 12 UTC, (B) 10/12/08 às 00 UTC e (C) 10/12/08 às 12 UTC.

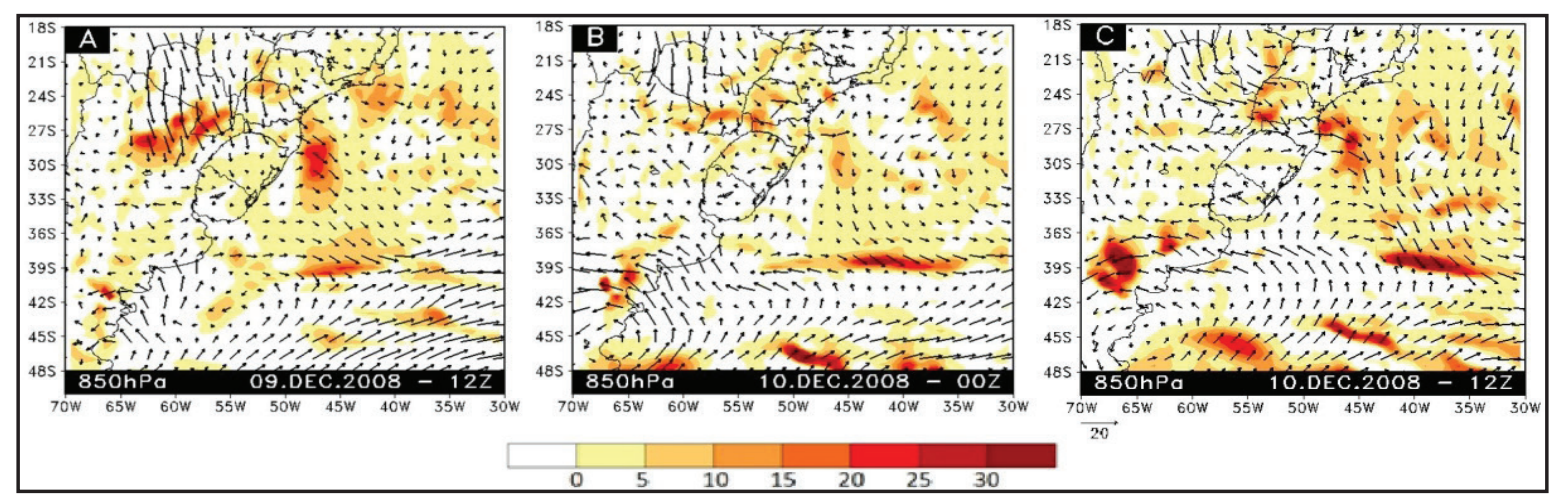

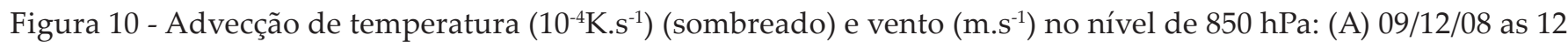
UTC, (B) 10/12/08 as 00 UTC e (C) 10/12/08 as 12 UTC 


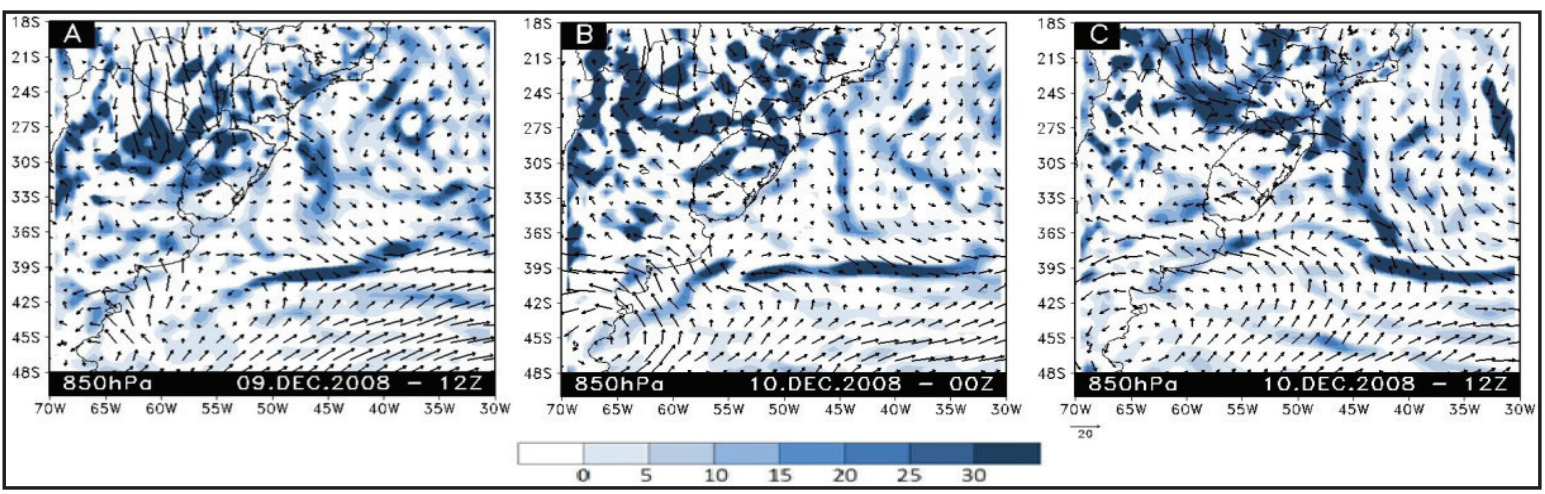

Figura11 - Convergência de umidade $\left(10^{-5} \mathrm{~g} \cdot \mathrm{kg}^{-1} \cdot \mathrm{s}^{-1}\right)$ (sombreado) e vento (m.s $\left.\mathrm{s}^{-1}\right)$ no nível de $850 \mathrm{hPa}$ (A) 09/12/08 as 12 UTC, (B) 10/12/08 as 00 UTC e (C) 10/12/08 as 12 UTC
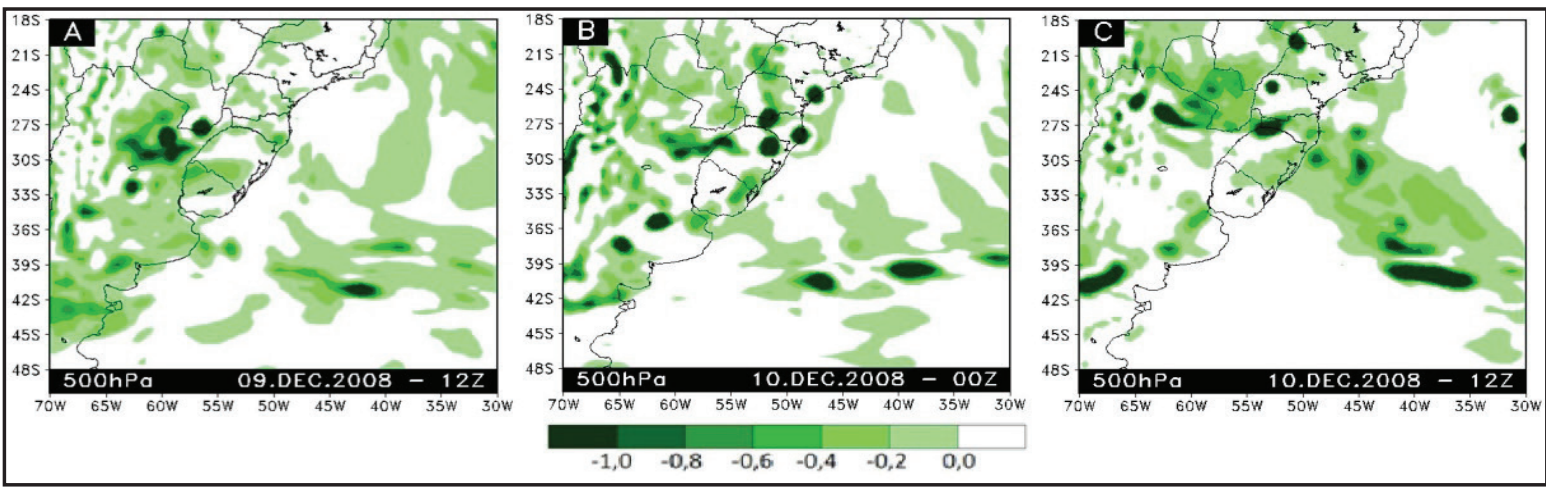

Figura 12 - Velocidade vertical (Omega) (Pa.s ${ }^{-1}$ ) (sombreado) no nível de 500 hPa: (A) 09/12/08 as 12 UTC, (B) 10/12/08 as $00 \mathrm{UTC}$ e (C) 10/12/08 as 12 UTC

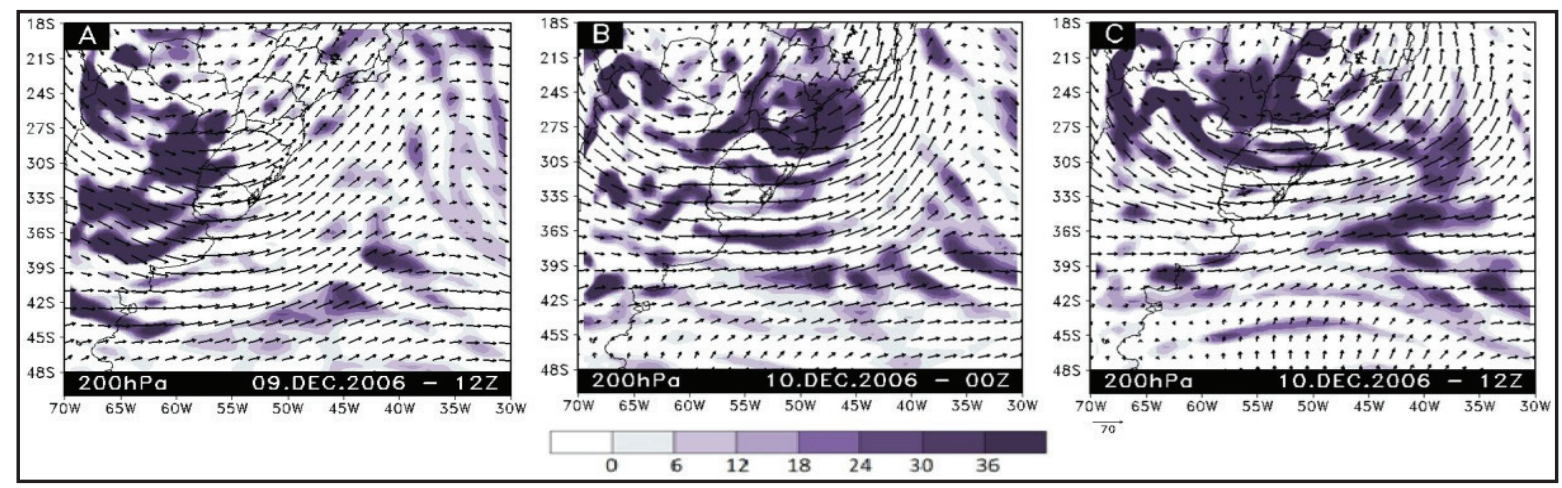

Figura 13 - Divergência $\left(10^{-5} \mathrm{~s}^{-1}\right)$ (sombreado) e vento (m.s $\left.\mathrm{s}^{-1}\right)$ no nível de 200 hPa: (A) 09/12/08 as 12 UTC, (B) 10/12/08 as $00 \mathrm{UTC}$ e (C) 10/12/08 as 12 UTC

vento em 850 hPa indicava a atuação do JBN em direção ao Oceano Atlântico, onde o SCM se dissipou. Foi observada uma diminuição dos valores de advecção de temperatura (Figura 10C) e convergência de umidade especifica (Figura 11C) sobre o RS em relação às etapas de iniciação e maturação. Observa-se ainda, em $850 \mathrm{hPa}$, que o JBN advectava calor e umidade para o estado do PR, deixando de atuar no RS, diminuindo a atividade convectiva e os movimento verticais ascendentes em 500 hPa (Figura 12C) e a divergência no nível de $200 \mathrm{hPa}$ (Figura 13C). Portanto, nesta fase, o ambiente onde o
$\mathrm{SCM}_{\mathrm{GRA}}$ estava inserido deixou de fornecer calor e umidade necessários para sustentar a atividade convectiva que o alimentava, podendo-se observar significativa diminuição de sua área, acompanhada de sua dissipação (Figura 4I).

Em suma, a queda de granizo em Sobradinho em 09/12/08 e a precipitação registrada em 10/12/08 no RS foi o resultado do aquecimento diurno e da atuação do JBN no nordeste da Argentina e norte do RS entre os dias 09 e 10/12/08 que transportava calor e umidade das regiões tropicais para as latitudes médias. Este trans- 
porte favoreceu o início do $\mathrm{SCM}_{\mathrm{GRA}-2008}$ que ocorreu no sul da AS, resultado este, semelhante ao encontrado por diversos autores (VELASCO; FRITSCH, 1987; FRITSCH; FORBES, 2001; NICOLINI et al. 2004; SALIO et al., 2007).

\section{Conclusão}

A queda de granizo em 09/12/08 no município de Sobradinho e a precipitação registrada em 10/12/08 no RS foi o resultado das condições atmosféricas extremamente favoráveis observadas na região (transporte de calor e umidade em baixos níveis e correntes ascendentes intensas), que levaram à formação e atuação do SCM GRA-2008 detectado nos dias 09 e 10/12/08.

Pôde-se observar que o SCM ${ }_{\text {GRA-2008 }}$ não estava associado à incursão de SF e foi modulado pelo aquecimento diurno e pela atuação do JBN presente no nordeste da Argentina e norte do RS entre os dias 09 e 10/12/08.

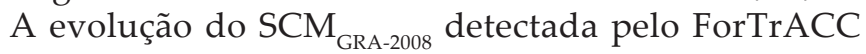
mostrou que este formou-se no Nordeste da Argentina dia 09/12/08, atingiu sua máxima atuação sobre o RS no mesmo dia e dissipou-se no oceano no dia 10/12/08. Apresentou um ciclo de vida de aproximadamente 22,5 horas e deslocamento de oeste para leste, semelhante à circulação de grande escala na região, que tende a mover os SCM na mesma direção.

O ambiente termodinâmico e sinótico associado ao evento propiciou à formação de tempestade severa com potencial para gerar granizo. Isso porque havia na região umidade e calor em abundância, trazidos pelo JBN, que favoreceram o disparo da convecção em baixos níveis da atmosfera. Esse cenário contribuiu para instabilizar a atmosfera e gerar movimentos verticais ascendentes intensos, os quais favoreceram a formação de nuvens com elevado desenvolvimento vertical, propícios à formação de granizo e precipitação.

Este estudo mostra que o monitoramento das condições atmosféricas associadas à ocorrência de granizo é extremamente importante para a geração de alertas e a mitigação dos danos à sociedade.

\section{Agradecimentos}

Os autores agradecem a CAPES e ao CNPq pelo auxílio financeiro.

\section{Referências}

BROOKS, H.E.; LEE, J.W.; CRAVEN, J.P. The spatial distribution of severe thunderstorm and tornado environments from global reanalysis data. Atmosphere Research, v.67, p. 73-94, 2003.

CAMPOS, C.R.J.; EICHHOLZ, C.W. Características físicas dos Sistemas Convectivos de Mesoescala que afetaram o Rio Grande do Sul no período de 2004 a 2008. Revista Brasileira de Geofísica (Impresso), v. 29, p. 331-345, 2011.

CARVALHO, L.; JONES, C. A satellite method to identify structural properties of mesoescale convective systems based on the maximum spatial correlation tracking technique (MASCOTTE). Journal of Applied Meteorology, v. 40, p. 1683-1701, 2001.

CORFIDI, S.F.; MERITT, J.H.; FRITSCH, J.M. Predicting the movement of mesoscale convective complexes. Weather and Forecasting, v. 11, p. 41-46, 1996.

COTTON, R. W.; ANTHES, B.R. Storm and cloud dynamics. Academic Press, Inc.

International Geophysics Series, 1989. v. 44, 883 p.

CRDCRS. Coordenadoria Regional da Defesa Civil do RS. Disponível em: <http://www.defesacivil.rs.gov. br >. Acesso em: 20 nov. 2013.

EDEN, P.; TWIST, C. Gran Enciclopedia de Bolsillo: Tiempo y Clima. Barcelona: Editora Molino, 1997. $160 \mathrm{p}$.

FAWBUSH, E.J.; MILLER, R.C. A method for forecasting hailstone size at the earth surface. Bulletin of American Meteorological Society, v. 34, p. 235-244, 1953.

FRITSCH, J.M; FORBES, G.S. Mesoscale Convective Systems: Severe Convective Storms, Meteorology Monographs, n.50, p.323-356, 2001.

GALWAY, J. G. The lifted index as a predictor of latent instability. Bulletin of the American Meteorological Society, v. 43, p. 528-529, 1956

HENRY, W. The Skew-T, Log P Diagram. National Weather Service Training Center, EUA, 68 p., 1987

HOUZE, R.A. Mesoscale convective systems. In: HOUZE, R.A. Cloud dynamics. Academic Press, Inc., v. 53, p. 334-404, 1994.

JACOBSEN, L. O.; BRAUN, S. Monitoramento de tempestades no sul do Brasil: caso de um sistema convectivo de mesoescala na zona sul do Rio Grande do Sul. In: CONGRESSO BRASILEIRO DE METEOROLOGIA, 14. 2006, Florianópolis. Anais... Florianópolis: SBMet, 2006.

JIRAK, I.L.; COTTON, W.R.. Environmental precursors to mesoscale convective system development. In: CONFERENCE ON AVIATION, RANGE, AND 
AEROSPACE, 11 AND CONFERENCE ON SEVERE LOCAL STORMS OPENING REMARKS, 22. 2004, Hyannis-MA-USA. Anais... Hyannis-USA. Disponível em: <http://ams.confex.com/ams/pdfpapers/81530.pdf >. Acesso em: 06 dez. 2013.

LAURENT H.; MACHADO, L.A.T.; MORALES, C.; DURIEUX, L. Characteristics of Amazonian Mesoscale Convective Systems Observed from Satellite and radar during the WETAMC/LBA Experiment. Journal of Geophysical Research, v. 107, n. 20, p. 8054, 2002.

LIMA, A. A.; MACHADO, L. A. T.; LAURENT, H. A divergência do vento em altos níveis e sua relação com a cobertura de nuvens e a precipitação, durante o WETAMC/LBA. Revista Brasileira de Meteorologia, v. 18, n. 2, p. 105-117, 2003.

KNIGHT, C.A.; KNIGHT, N.C. Hailstorms. In: DOSWELL III, C.A. Severe Convective Storms. American Meteorological Society. Meteorological Monographs. v. 28, p. 223-249, 2001.

MACHADO, L.A.T.; ROSSOW, W.B. Structural characteristics and radiative of tropical cloud clusters. Monthly Weather Review, v. 121, n. 12, p. 3234-3260. 1993.

MACHADO, L.A.T.; LAURENT, H. The convective system area expansion over Amazonia and its relationships with convective system life duration and high-level wind divergence. Monthly Weather Review, v. 132, n. 4, p. 714-725, 2004.

MACHADO, L.A.T.; GUEDES, R.L.; SILVEIRA, J.M.B.; WALTZ, R.C.; ALVES, M.A.S. Ciclo de vida de sistemas convectivos. In: CONGRESSO BRASILEIRO DE METEOROLOGIA, 8. 1994, Belo Horizonte. Anais... Belo Horizonte: SBMet, 1994, p. 323- 326.

MADDOX, R.A. An objective technique for separating macroscale and mesoscale features in Meteorological data. Monthly Weather Review, v. 108, p. 1108-1121, 1980 .

NASCIMENTO, E.L. Previsão de tempestades severas utilizando-se parâmetros convectivos e modelos de mesoescala: Uma estratégia operacional adotável no Brasil? Revista Brasileira de Meteorologia, v. 20, n. 1, p. 121-140, 2005.

NCEP-CFSR. National Centers for Environmental Prediction - Climate Forecast System Reanalysis. Disponível em: <http://nomads.ncdc.noaa.gov/data. php? name=access\#cfsr $>$. Acesso em: 24 set. 2013.

NESBITT, S.W.; CIFELLI, R.; RUTLEDGE, S.A. Storm morphology and rainfall characteristics of TRMM precipitation features. Monthly Weather Review, v.134, p.2702-2721, 2006.

NICOLINI, M.; SAULO, A.C.; TORRES, J.C.; SALIO, P. Enhanced precipitation over Southeastern South América related to strong low-level jet events during austral warm season. Meteorologica, Special Issue for the South American Monsoon System, v. 27, p. 59-69, 2002.

NICOLINI, M.; SALIO, P.; TORRES, J.C.; ZIPSER, E. The relationship between South American low-level jet events with the formation and maintenance of mesoscale convective systems. In: INTER CLOUDS AND PRECIPITATION CONFERENCE. 2004, Bologna, Italy. Anais... Bologna, 2004.

PINTO, L.B; CAMPOS, C.R.J. Análise do comportamento morfológico e radiativo de um Sistema Convectivo de Mesoescala inferido via imagens de satélite. Revista Brasileira de Geofísica, v. 27, n. 1, p. 35-42, 2009.

RAMOS, A. M.; SANTOS, L.A.R.; FORTES, L.T.G. Normais Climatológicas do Brasil 1961-1990. BrasíliaDF: Instituto Nacional de Meteorologia, 2009, 465 p.

RASERA, G. Eventos severos gerados por SCM que atingiram o Rio Grande do Sul no período de 2004 a 2008. 2013. 94 f. Dissertação (Mestrado em Meteorologia), Programa de Pós-graduação em Meteorologia, Universidade Federal de Pelotas, 2013.

RASERA. G.; CAMPOS, C. R. J. Análise sazonal das regiões do Rio Grande do Sul atingidas por eventos severos gerados por SCM no período de 2004 a 2008. Anuário do Instituto de Geociências (Online), v. 36, n.2, p. 61-69, 2013. Disponível em: <http://dx.doi. org/10.11137/2013_2_61_69>. Acesso em: 19 nov. 2013.

RIOGRANDEDOSUL.SECRETARIADAAGRICULTURA EABASTECIMENTO. Macrozoneamento agroecológico e econômico do estado do Rio Grande do Sul/Secretaria da Agricultura e Abastecimento. Porto Alegre, v. 2, 1994.

SAKAMOTO, M.S. Sistemas Convectivos de Mesoescala observados na Região Subtropical da América do Sul durante o SALLJEX. 2009, 243p. Tese (Doutorado em meteorologia), Programa de Pós-graduação em Meteorologia, Universidade de São Paulo, São Paulo.

SALIO, P.; NICOLINI, M.; ZIPSER, E. J. Mesoscale Convective Systems over Southeastern South America and Their Relationship with the South American Low- Level Jet. Monthly Weather Review, v. 135, p. 1290-1309, 2007. 
SILVA DIAS, M. A. F. Storms in Brazil. In: PIELKE, R. SR. \& PIELKE, R. JR. (Coordenadores). Storms - hazard and disasters series. Londres: Routledge, 1999. v. 1, p. 207-219.

SILVA DIAS, M. A. F. Índices de instabilidade para previsão de chuva e tempestades severas. Disponível em: <http://master.iag.usp.br/ensino/indices.pdf $>$. Acesso em: 09 dez. 2013.

SIQUEIRA, J. R.; MARQUES, V. S. Occurrence frequencies and trajectories of mesoscale convective systems over southeast Brazil related to cold frontal and non-frontal incursions. Australian Meteorological Magazine, v. 57, p. 345-357, 2008.

UCCELLINI, L.W.; JOHNSON, D.R. The coupling of upper and lower tropospheric jet streams and implications for the development of severe convective storms. Monthly Weather Review, v. 107, p. 682-703, 1979.

VARGAS JR., V.R.; CAMPOS, C.R.J.; RASERA, G.; EICHHOLZ, C.W. Eventos severos que afetaram o RS no período de 2004 a 2008. In: WORKSHOP BRASILEIRO DE MICROMETEOROLOGIA, 7. 2011, Santa Maria. Anais... Santa Maria: UFSM, 2011. Disponível em: <http://workshop.micrometeorologia. com/wpcontent/uploads/M\%C3\%93DULO_ANAIS. pdf >. Acesso em: 20 dez. 2013.

VELASCO, I.; FRITSCH, J.M. Mesoscale convective complexes in the Americas. Journal Geophysical Research, v. 92, p. 9591-9613, 1987.

VILA, D.A. Sistemas convectivos precipitantes de mesoescala sobre Sudamerica: Ciclos de vida y circulación en gran escala asociada (Rainy mesoscale convective systems over South America: Life cycle and the associated large scale environment). 2004, 132p. Tese (Doutorado em Meteorologia). Programa de Pós-graduação em Ciências, Faculdade de Ciências Exatas e Naturais, Universidade de Buenos Aires, Buenos Aires.

VILA, D.A.; MACHADO, L.A.T.; LAURENT, H.; VELASCO, I. Forecast and Tracking the Evolution of Cloud Clusters (ForTraCC) Using Satellite Infrared Imagery: Methodology and Validation. Weather and Forecasting, v. 23, p. 233-245, 2008.

WALLACE, J.M.; HOBBS, P.V. Atmospheric science: an introductory survey. Academic Press- Inc, 2006, v. $2,365 \mathrm{p}$.

ZIPSER, E. J.; LIU, C.; DCECIL, D. J., NESBITT, S. W.; YORTY, D. P. Where are the Most Intense
Thunderstorms on Earth? Bulletin of American Meteorological Society, v. 87, p. 1057-1071, 2006. 